\title{
Glycyrrhetinic Acid Maintains Intestinal Homeostasis via HuR
}

\author{
Gang Chen', Bei Bei', Yuan Feng ${ }^{1}$, Xuezheng $\mathrm{Li}^{2}$, Zhe Jiang ${ }^{2}$, Jian-Yong Si ${ }^{3}$, \\ De-Gang Qing ${ }^{4}$, Juan Zhang ${ }^{3,4 *}$ and Ning Li ${ }^{1 *}$
}

${ }^{1}$ School of Traditional Chinese Materia Medica, Key Laboratory of Computational Chemistry-Based Natural Antitumor Drug Research \& Development, Shenyang Pharmaceutical University, Shenyang, China, ${ }^{2}$ Department of Pharmacy, Yanbian University, Yanji, China, ${ }^{3}$ Institute of Medicinal Plant Development, Chinese Academy of Medical Sciences Peking Union Medical College, Beijing, China, ${ }^{4}$ XinJiang Institute of Chinese Materia Medica and Ethnodrug, Ürümqi, China

Glycyrrhetinic acid (GA) is one of the main components of the traditional Chinese medicine of licorice, which can coordinate and promote the effects of other medicines in the traditional prescription. We found that GA could promote the proliferation, decrease the apoptotic rate, and attenuate DFMO-elicited growth arrest and delay in restitution after wounding in IEC-6 cells via HuR. GA failed to promote proliferation and to suppress apoptosis after silencing HuR by siRNA in IEC-6 cells. Furthermore, with the model of small intestinal organoids developed from intestinal crypt stem cells, we found that GA could increase HuR and its downstream ki67 levels to promote intestinal organoid development. In the in vivo assay, GA was shown to maintain the integrity of the intestinal epithelium under the circumstance of $48 \mathrm{~h}$-fasting in rats via raising HuR and its downstream genes such as EGF, EGFR, and MEK. These results suggested that via HuR modulation, GA could promote intestinal epithelium homeostasis, and therefore contribute to the absorption of constituents from other medicines co-existing in the traditional prescription with licorice in the small intestine. Our results provide a new perspective for understanding the effect of licorice on enhancing the therapeutic effect of traditional prescriptions according to the traditional Chinese medicine theory.

Keywords: glycyrrhetinic acid, HuR, organoid, fasting, DMFO, licorice

\section{INTRODUCTION}

Glycyrrhetinic acid is one of the main components of licorice (Glycyrrhiza uralensis Fisch and Glycyrrhiza inflata Batal). Having been used in China for around 2,000 years as a traditional Chinese medicine (TCM), nowadays, licorice is also utilized as a resource of food according to the regulations released by the China Food and Drug Administration. Licorice is also known for its high utilization rate, which is commonly described as "nine out of ten prescriptions must have licorice included." According to traditional Chinese drug theory, licorice has a "coordinating effect" by modulating the effects of other medicines coexisting with it in the same prescription, and thereby

Abbreviations: ARE, AU-rich elements; DAPI, 4',6-diamidino-2-phenylindole; DFMO, difluoromethylornithine; EGF epidermal growth factor; EGFR, epidermal growth factor receptor; FITC, fluorescein isothiocyanate; GA, glycyrrhetinic acid; HuR, Hu-antigen R; LPS, lipopolysaccharide; MEK, MAPK and ERK kinase; MTT, methyl thiazolyl tetrazolium. 
improves the therapeutic effect of the prescription, and this special feature of it becomes the main reason of its utilization rate. How could that be happening? So far there is no convincing theory and evidence to explain it. One theory is that licorice might be able to enhance the absorption of molecules from other traditional medicines. As almost all the traditional medicines are used by the way of decoction, it is believed that in the traditional prescription, licorice might be able to maintain and/or restore the intestine homeostasis so as to assure the effective absorption of molecules from other ingredients.

The precise regulation of intestinal epithelium cells (IECs) depends on many factors, such as polyamides, microRNAs, RNAbinding protein, and the stimulation of foods. It is well known that starvation is detrimental to the integrity and the homeostasis of the intestinal mucosa (Mccue et al., 2017), exemplifying the fact that, when feeling sick, we usually have a bad appetite, which lowers our food intake. For those who had a severe disease or were in a coma in ancient times, following a regular diet was not achievable, resulting in the defective intestinal epithelial integrity. Thus, under these conditions, restoring the intestinal integrity and homeostasis are the primary issues to address when using a decoction of traditional medicines that are needed to be absorbed mainly via the small intestine.

Glycyrrhizic acid (a triterpene glycoside with GA as the aglycone) and GA are two well-known components in licorice. As most of the glycosides are hydrolyzed in vivo to produce the aglycone, GA is also considered as the active form of glycyrrhizic acid. Thus, in this paper, the in vitro, ex vivo (organoids), and in vivo models were utilized to investigate the effect of GA on intestinal restitution, offering a new perspective on the coordinating effect of licorice.

\section{MATERIALS AND METHODS}

\section{Animals and Ethics Statement}

$\mathrm{SD}$ rats were obtained from the Guangdong experimental animal research center. All experiments were performed in a specific pathogen-free unit of Guangzhou University of Chinese Medicine. The study protocol was approved by the Ethics Committee for Animal Experiments of Guangzhou University of Chinese Medicine (2016-0502).

\section{Chemicals and Cell Culture}

The IEC- 6 cell line and Caco- 2 cell line were purchased from the Kunming Cell Bank. IEC-6 cells were at passage 15 and were maintained in T-150 flasks in Dulbecco's modified Eagle's medium (DMEM) supplemented with 5\% heat-inactivated FBS. IEC-6 cells were used at passages 15-20.

High-sugar DMEM cell culture medium was purchased from Hyclone, United States. Fetal bovine serum (FBS), $0.25 \%$ Trypsin-EDTA was purchased from BioInd (Biological Industries, Israel). HuR, $\beta$-actin antibody was purchased from Cell Signaling Technology, United States. Claudin-1 and Ki-67 antibodies were purchased from Abcam, United Kingdom. GAPDH antibody was purchased from Shenyang Wanlei Biotechnology Co., Ltd. The corresponding secondary antibodies were purchased from Proteintech, United States. PVDF membrane and an immunoblotting chemiluminescence (ECL) system were purchased from Bio-Rad. The reverse transcription kit and Real-time fluorescence quantification kit were purchased from TaKaRa, Japan. siHuR, siSPRY4-IT1, SPRY4-IT1, and Claudin-1 primers were designed and synthesized by Guangzhou Ruibo Biotechnology Co., Ltd. The apoptosis detection kit was purchased from BD Biosciences, United States. The cell cycle detection kit was purchased from Beyotime, Beijing. GA (purity $\geq 98 \%$ ) was obtained from Phystandard Technology LTD (Tianjin, China).

\section{Intestinal Organoid Culture}

C57BL/6 mice were sacrificed according to applicable ethical regulations and about $20 \mathrm{~cm}$ of small intestine were harvested to isolate the intestinal crypts. Crypt fractions were resuspended in cold DMEM/F-12 and the number of crypts per $\mathrm{mL}$ were calculated. The dome containing crypts were incubated and suspended in a 1:1 mixture of Matrigel ${ }^{\circledR}$ Matrix (BD Biosciences, United States) and IntestiCult ${ }^{\mathrm{TM}}$ organoid growth medium (Stemcell Technologies, Canada ) at $37^{\circ} \mathrm{C}$ and $5 \% \mathrm{CO}_{2}$, respectively. The culture medium were fully replaced three times per week.

\section{Flow Cytometry Assay}

Annexin V/PI staining assay was employed to determine apoptosis, and apoptosis analysis was carried out using a FITCAnnexin V apoptosis detection kit (BD Biosciences, San Jose, CA, United States) according to the manufacturer's instructions. Briefly, $1 \times 10^{6}$ cells/well of IEC-6 were cultured in a 6-well plate. The next day, the cells were treated with GA $(1,10$, and $20 \mu \mathrm{M})$ and incubated for $24 \mathrm{~h}$. At indicated times, cells were harvested, and both attached and floating cells were collected, washed twice with ice-cold PBS, and cells were re-suspended in a $100 \mu \mathrm{L}$ binding buffer. The next $5 \mu \mathrm{L}$ of FITC Annexin V and $5 \mu \mathrm{L}$ PI were added and incubated for $15 \mathrm{~min}$ at $\mathrm{RT}\left(25^{\circ} \mathrm{C}\right)$ in the dark. And $400 \mu \mathrm{L}$ of binding buffer were added to each tube. The data were collected on a BD FACSVerse flow cytometer (BD Biosciences, San Jose, CA, United States) and were analyzed using FlowJo software. The apoptosis rate was obtained through the following formula:

$$
\text { Apoptosis rate } \%=\text { (number of apoptotic cells)/ }
$$

$$
\text { (number of total cells observed) } \times 100 \%
$$

\section{Cell Cycle Analysis}

Cells were harvested at $24 \mathrm{~h}$ post-treatment, fixed with $70 \%$ ethanol overnight. The sample was washed with ice-cold PBS and then stained with the cell cycle detection kit (Beyotime, China). The cells were incubated for $30 \mathrm{~min}$ at $37^{\circ} \mathrm{C}$ in the dark. The data were collected on a BD FACSVerse flow cytometer (BD Biosciences, San Jose, CA, United States) and analyzed using FlowJo software. The proliferation index was obtained through the following formula:

$$
\text { Proliferation index } \%=(\mathrm{S}+\mathrm{G} 2 / \mathrm{M}) /(\mathrm{G} 0 / \mathrm{G} 1+\mathrm{S}+\mathrm{G} 2 / \mathrm{M})
$$

$$
\times 100 \%
$$




\section{Western Blot Analysis}

Cells were washed with ice-cold PBS and lysed with lysis buffer $(20 \mathrm{mM}$ Tris-Hcl, pH 7.5, $130 \mathrm{mM} \mathrm{NaCl}, 1 \% \mathrm{vol} / \mathrm{vol}$ TritonX-100, $0.5 \% \mathrm{wt} / \mathrm{vol}$ deoxycholate, $0.1 \% \mathrm{wt} / \mathrm{vol}$ SDS, $1 \mathrm{mM}$ DTT, $10 \mathrm{mM}$ sodium pyrophosphate, $5 \mathrm{mM}$ sodium fluoride, $1 \mathrm{mM}$ phenyl-methylsulfonyl fluoride, and $200 \mathrm{M}$ sodium orthovanadate. $\mathrm{L}$ ). The protein content was determined by BCA assay. Equal amounts of protein and the Precision Plus Protein Standards (Bio-Rad) were resolved by SDSPAGE gels $(8 \%$ gel) and transferred onto PVDF membranes (Bio-Rad, United States). After soaking in blocking buffer (5\% non-fat milk), the membrane was incubated overnight with primary antibody HuR (Cell Signaling Technology, United States), followed by horseradish peroxidase-conjugated secondary antibodies. Membranes were exposed to goat anti-rabbit or anti-mouse (Proteintech, United States) secondary anti-bodies. An antibody against $\beta$-actin or GAPDH (Cell Signaling Technology, United States) served as an endogenous reference.

\section{Cell Growth Assay}

Cell viability was measured with MTT assays. Briefly, cells were cultured in 96-well plates $\left(2.5 \times 10^{3}\right.$ cells/well $)$ in complete DMEM. After treatment with various concentrations of GA $(1,10,20,40,60,80$, and $100 \mu \mathrm{M})$ for 24,48 , and $72 \mathrm{~h}$, the medium was removed and the cells were incubated with $5 \mathrm{mg} / \mathrm{mL}$ MTT for $4 \mathrm{~h}$ at $37^{\circ} \mathrm{C}$ and $5 \% \mathrm{CO}_{2}$. The formazan formed by live cells was dissolved by adding $100 \mu \mathrm{L}$ of DMSO to each well, and the optical density at $490 \mathrm{~nm}\left(\mathrm{OD}_{490}\right)$ was measured to estimate the number of viable cells. The assay was repeated in three-independent experiments.

\section{Measurement of Epithelial Repair in vitro}

Cells were plated at $5.0 \times 10^{4} / \mathrm{cm}^{2}$ in DMEM containing FBS on $60-\mathrm{mm}$ dishes at $37^{\circ}$ and $5 \% \mathrm{CO}_{2}$. The monolayer was wounded by removing part of the monolayer on day 3; Cells were washed 3 times with PBS and serum-free medium were added; repair was assayed 24 and $48 \mathrm{~h}$ after wounding. The results were reported as the cell number of wound width covered.

\section{Caco-2 Barrier Function Assay}

The epithelial barrier function in vitro was examined by trans-epithelial electrical resistance (TEER) using a 24-well transwell plate. The Caco-2 cells were seeded at a density of $2 \times 10^{4}$ cells/well in 24-well transwell insert (pore size $0.4 \mu \mathrm{m}$, Corning). After $48 \mathrm{~h}$ of culture, the TEER was measured with an epithelial voltmeter (World Precision Instruments, United States), and then the cells were treated with GA $(10 \mu \mathrm{M}) .2 \mathrm{~h}$ later, cells were treated with LPS $(2 \mu \mathrm{g} / \mathrm{mL})$. The TEER was measured after LPS and GA co-treatment for $2,4,6$, and $24 \mathrm{~h}$, respectively. The resistance measurements of cell-free filters (blank resistance) were subtracted from that seeded with cells. The resistance value of the filters and fluids was be subtracted in the calculation for each measurement.

\section{RNA Interference}

The expression of HuR was silenced by transfection with specific siRNA. The siHuR was purchased from Ribobio. For each $60-\mathrm{mm}$ cell culture dish, $5 \mu \mathrm{L}$ of the $50 \mu \mathrm{M}$ stock duplex siHuR was used. $48 \mathrm{~h}$ after transfection using riboFECT ${ }^{\mathrm{TM}} \mathrm{CP}$ Reagent, cells were harvested for analysis.

\section{Immunofluorescence Staining}

Intestinal organoid smear was fixed with paraformaldehyde, and immunofluorescently stained for $\mathrm{HuR}$ and $\mathrm{Ki}-67$ as the protocol. Briefly, the organoid smears were permeabilized with $0.1 \%$ Triton $\mathrm{X}-100$ for $20 \mathrm{~min}$ at room temperature, and treated with $\mathrm{HuR}$ $(1: 100)$ and Ki-67 (1:800) antibodies at $4^{\circ} \mathrm{C}$ overnight. The image was obtained by laser confocal microscope.

\section{Statistical Analysis}

Data are expressed as means \pm SEM. Differences between two groups were analyzed using Student's $t$-test. For the comparison of multiple groups, an analysis of variance (ANOVA) tests were used, followed by the Student-Newman-Keuls test. $P<0.05$ was considered to be statistically significant.

\section{RESULTS}

\section{GA Promotes Cell Proliferation and Restitution After Wounding}

The effect of GA on normal IECs was evaluated in IEC- 6 cells by MTT method. The results showed that $10 \mu \mathrm{M}$ GA promoted cell growth at $24 \mathrm{~h}$. Both 1 and $20 \mu \mathrm{M}$ GA did not alter the proliferation of IEC- 6 cells, while 40-100 $\mu$ M GA inhibited IEC-6 cell growth after $24 \mathrm{~h}$. As for $48 \mathrm{~h} \mathrm{GA}$ treatment, both 10 and $20 \mu$ M GA enhanced the IEC-6 proliferation, compared with 80 and $100 \mu \mathrm{M}$ GA that significantly inhibited IEC-6 proliferation. Interestingly, lower doses of GA $(1-40 \mu \mathrm{M})$ could increase the IEC- 6 cell growth, while higher doses of GA (60-100 $\mu \mathrm{M})$ failed to increase IEC-6 cell growth (Figure 1A). All these results suggested that lower doses of GA, especially $10 \mu \mathrm{M} \mathrm{GA}$, could promote IEC- 6 cell growth. Thus, 1-20 $\mu \mathrm{M}$ GA were adopted to conduct the subsequent experiments.

In order to examine the effect of GA on growth-arrested IEC-6 cells, DFMO was used to deplete the polyamine and thereby inhibit the proliferation of IEC- 6 cells. The results showed that DFMO drastically decreased the proliferation of IEC- 6 cells. Both 1 and $10 \mu \mathrm{M}$ GA could partially reverse the growth inhibition caused by DFMO in IEC-6 cells (Figures 1B,C).

Wound healing assay revealed that DFMO suppressed intestinal epithelial restitution, as indicated by a decrease in IEC-6 cell migration, whereas GA could reverse the IEC-6 cell migration arrest elicited by DFMO (Figures 1D,E).

\section{GA Increases S Phase in IEC-6 Cells}

A flow cytometry experiment showed that GA $(1-20 \mu \mathrm{M})$ increased the S-phase while decreasing the G1 phase in IEC-6 cells (Figures 2A,B), and led to an increase in cell proliferation as suggested by the index (Figure 2C). 

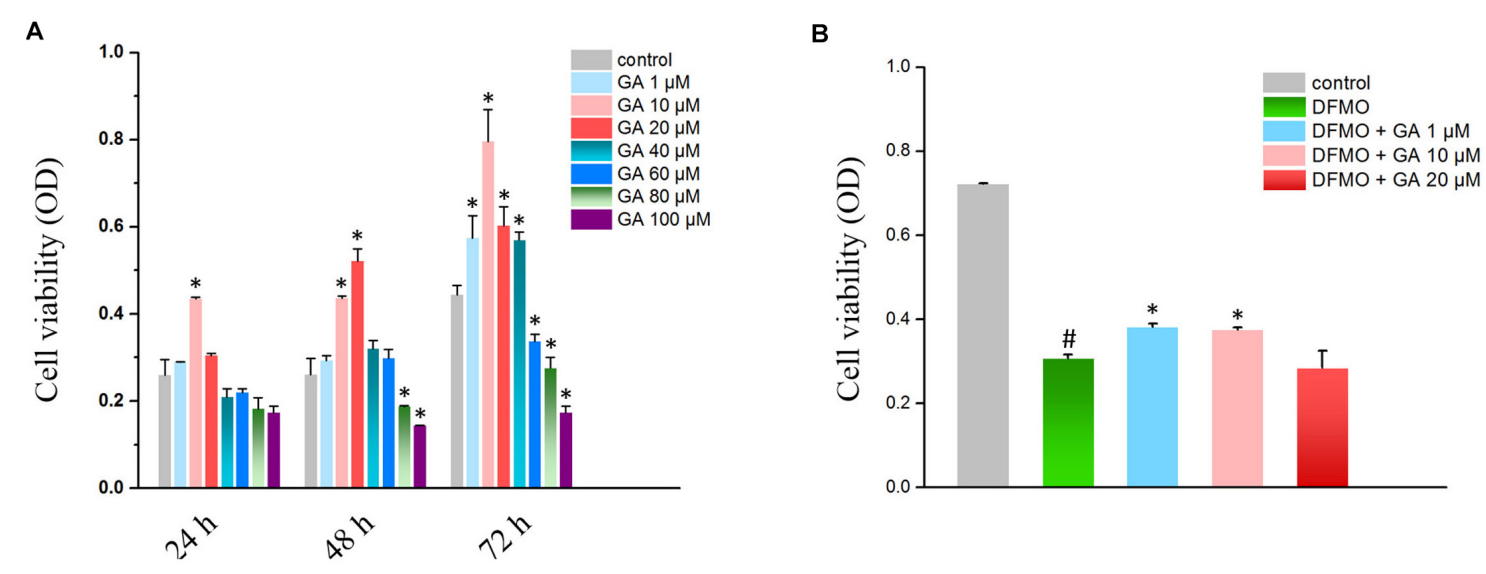

c
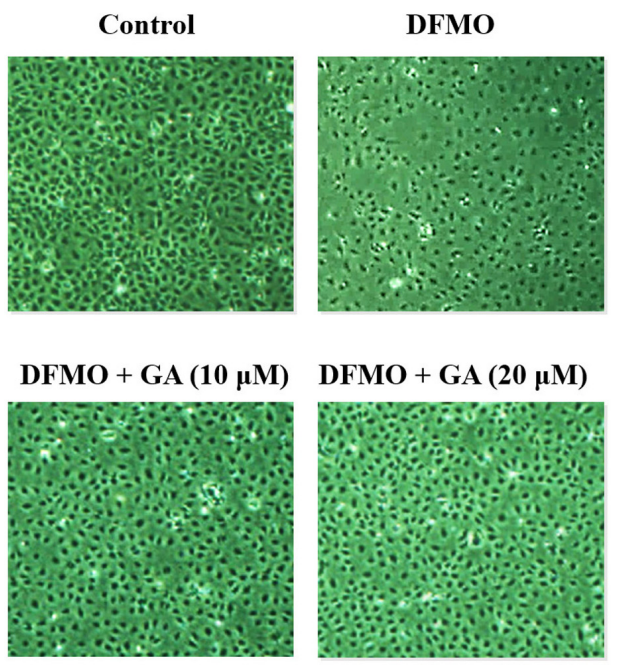

D

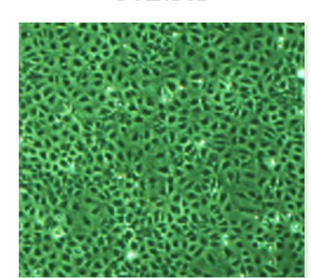

E

Control

DFMO
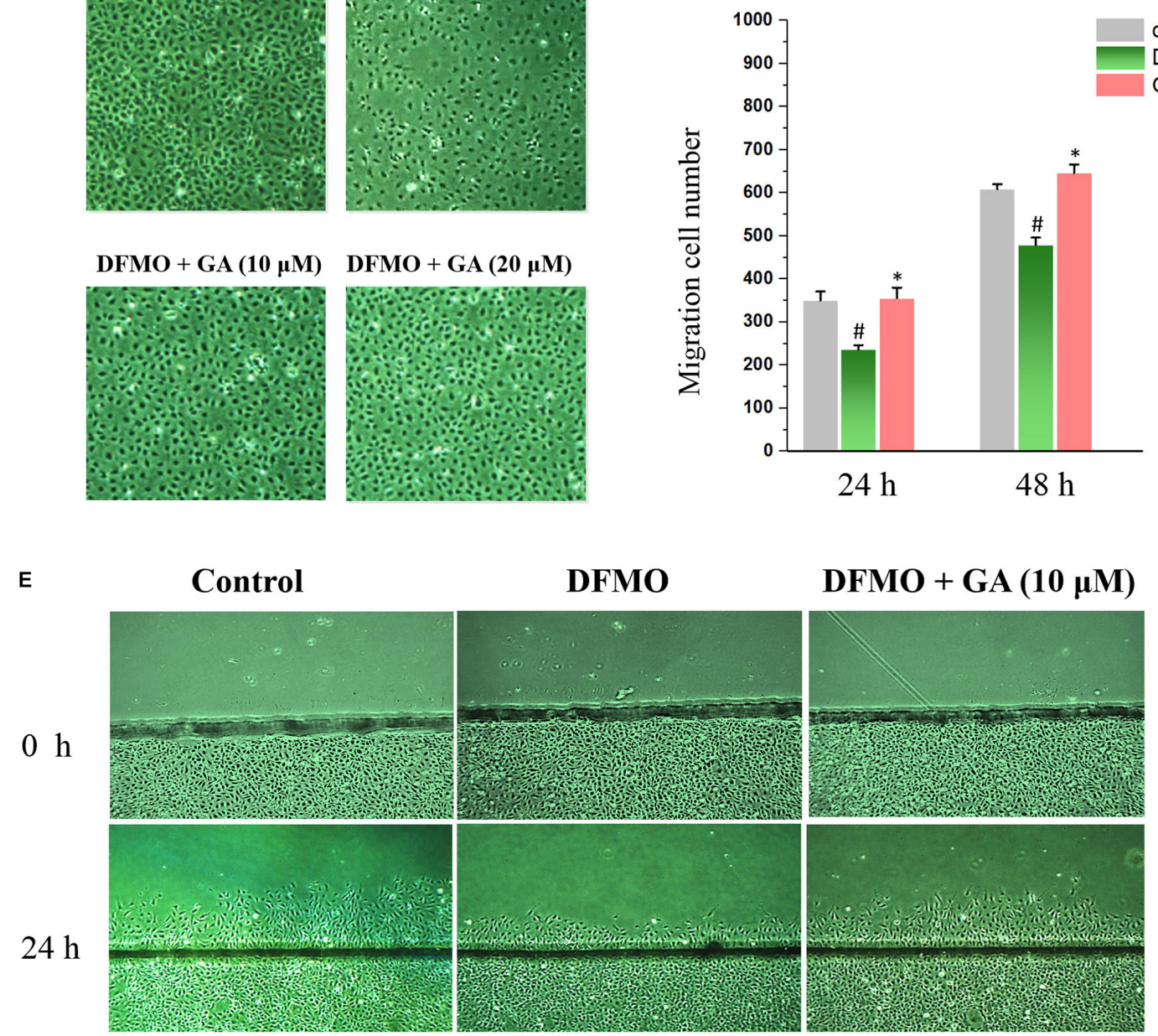

$0 \mathrm{~h}$
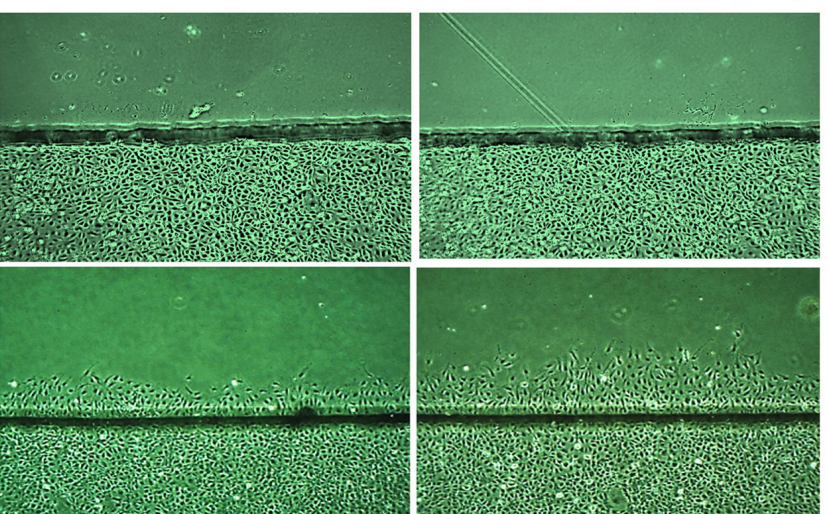

$48 \mathrm{~h}$
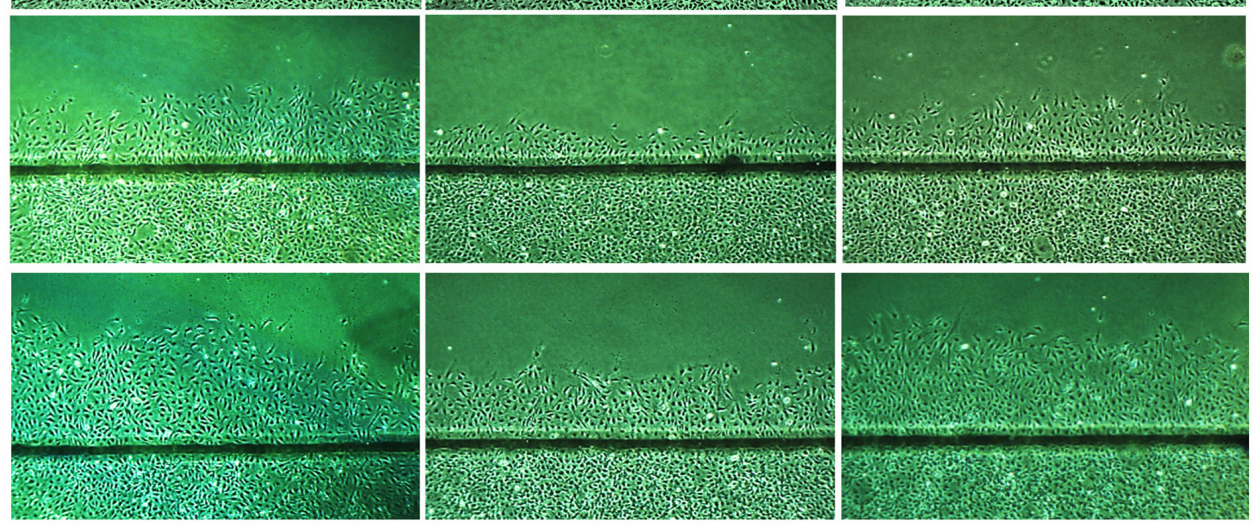

FIGURE 1 | Continued 
FIGURE 1 | Glycyrrhetinic acid promotes cell proliferation and regeneration after wounding in IEC-6 cells. (A) Cell viabilities of IEC-6 cells treated with GA of different concentrations. (B) Cell viabilities of IEC-6 cells treated with DFMO and GA of different concentrations. (C) Images of IEC-6 cell growth for DFMO and GA groups.

(D) Summarized data showing rates of migration after wounding for DFMO and GA groups described in panel (E). Values are means \pm SEM from six dishes.

(E) Images of cell migration after wounding for DFMO and GA groups. For panel (A) ${ }^{*} P<0.05$ compared with control IEC-6 cells. For panel (D) \# $P<0.05$ compared with control group and $* P<0.05$ compared with DFMO group.

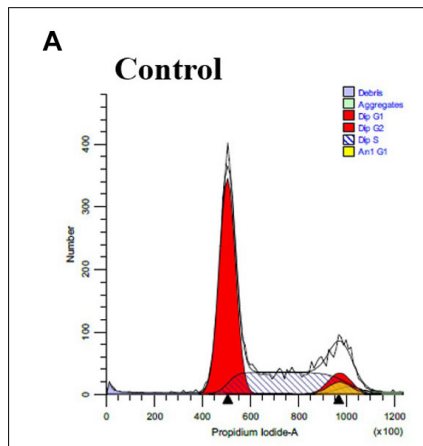

GA (10 $\mu \mathrm{M})$

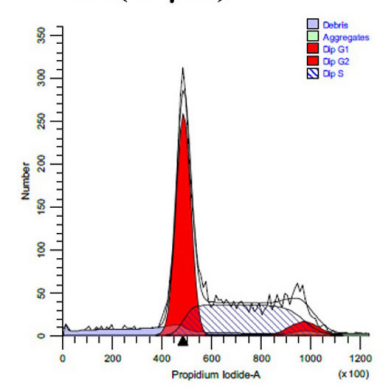

GA $(1 \mu M)$

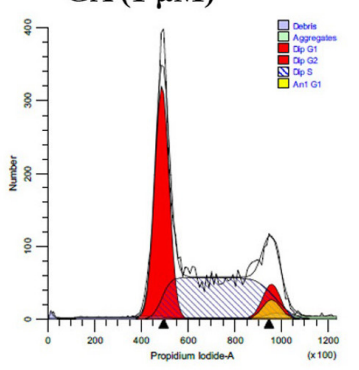

GA $(20 \mu M)$

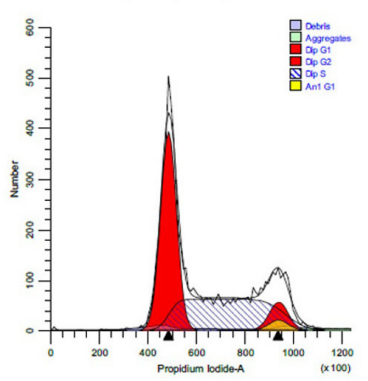

B

\begin{tabular}{|c|c|c|c|c|}
\hline & Control & GA $1 \mu \mathrm{M}$ & GA $10 \mu \mathrm{M}$ & GA $20 \mu \mathrm{M}$ \\
\hline G1/\% & $60.25 \pm 1.92$ & $43.11 \pm 0.36$ & $46.11 \pm 3.19$ & $48.32 \pm 0.31$ \\
\hline S/\% & $31.42 \pm 1.98$ & $46.10 \pm 1.51$ & $46.61 \pm 2.17$ & $43.18 \pm 0.78$ \\
\hline G2/\% & $8.00 \pm 0.18$ & $10.30 \pm 1.87$ & $7.30 \pm 1.02$ & $8.00 \pm 0.17$ \\
\hline
\end{tabular}

C

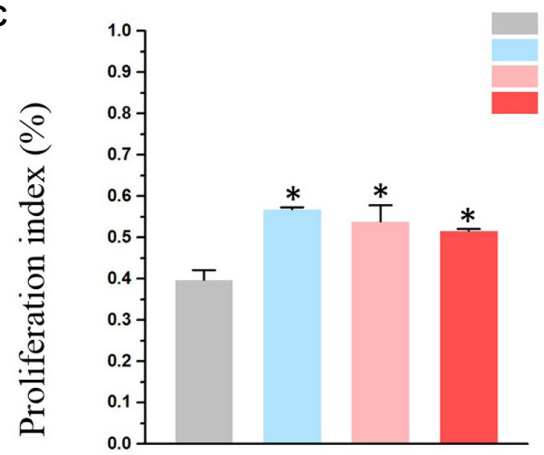

FIGURE 2 | Flow cytometry results show that GA induces S phase arrest in IEC-6 cells treated with GA for 24 h. (A) GA induces S phase arrest in IEC-6 cells. (B) Detailed cell cycle distribution in IEC-6 cells described in panel (A). (C) Summarized data showing proliferation index of IEC-6 cells described in panel (A). Values are means $\pm \mathrm{SD} ; n=6\left({ }^{*} P<0.05\right.$ compared with the control group).

\section{GA Increases HuR Expression in IEC-6 Cells and Restores the Distribution of HuR in DMFO-Treated IEC-6 Cells}

The HuR protein is the ubiquitously expressed member of the ELAV-like family of RNA-binding proteins (RBPs). Recent studies showed that $\mathrm{HuR}$ is one of the key regulators maintaining the intestinal homeostasis post-transcriptionally (Liu et al., 2016). GA increased $\mathrm{HuR}$ protein levels both in cytoplasm (Figures 3A,B) and nucleus (Figures 3C,D), exhibiting the same modulatory effect as spermidine (SPD) (Figures 3A-D), one of the polyamines that promotes the proliferation of IECs (Song et al., 2014). The depletion of polyamines by DFMO increased HuR levels in cytoplasm (Figures 3E,F) while decreasing HuR levels in nucleus (Figures $\mathbf{3 G}, \mathbf{H}$ ). It is noteworthy is the fact that GA reversed DFMO-induced aberrant $\mathrm{HuR}$ distribution and restored the HuR levels in cytoplasm and nucleus (Figures 3E-H).

\section{Silencing HuR Eliminates the Effect of GA in IEC-6 Cells}

In order to examine the relationship between $\mathrm{HuR}$ and GA's effect on IECs, siRNAs were used to silence $\mathrm{HuR}$
(Figures 4A,B). Compared with the control siRNA (C-siRNA) group, co-treatment of GA and C-siRNA significantly reduced the early apoptosis rate in IEC-6 cells, while silencing HuR with siRNA totally reversed the GA-induced suppression on IEC-6 cell apoptosis (Figures 4C,D). MTT results showed that GA (1-20 $\mu \mathrm{M})$ enhanced IEC-6 proliferation at $72 \mathrm{~h}$ compared to the C-siRNA group, while GA did not promote IEC-6 cell proliferation after the silence of $\mathrm{HuR}$ at $72 \mathrm{~h}$ (Figure 4E). These results suggested that GA inhibits apoptosis and promotes proliferation via HuR in IEC-6 cells.

\section{GA Promotes Rapid Restitution of Trans-Epithelial Electrical Resistance (TEER) Impaired by Lipopolysaccharide via Increasing HuR}

The normal intestinal epithelium possesses a barrier function, defending our body from the invasion of endotoxin and of the xenobiotics in the intestine. The maintenance of the intestine barrier function relies on the fast overturn rate of the intestinal epithelium, which would keep the integrity of the intestinal epithelium to maintain its barrier function. Thus, we wondered if GA could promote the formation of the intestinal barrier 
A

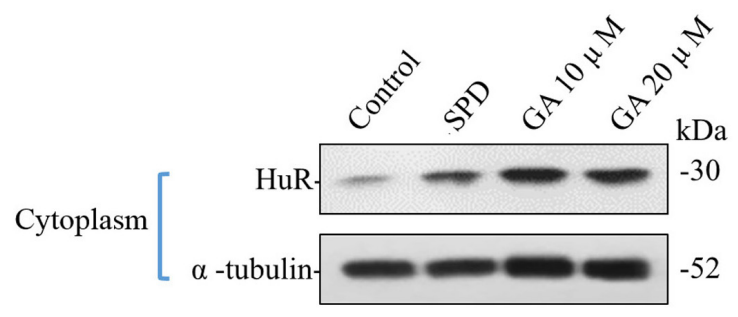

C

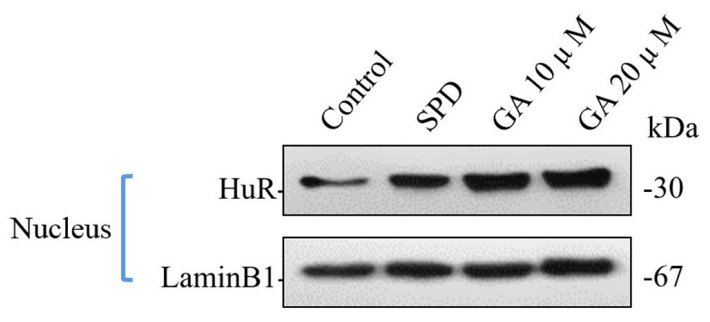

E

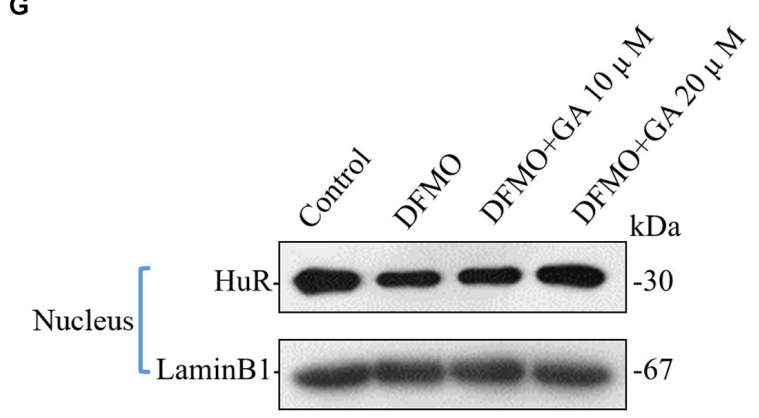

B

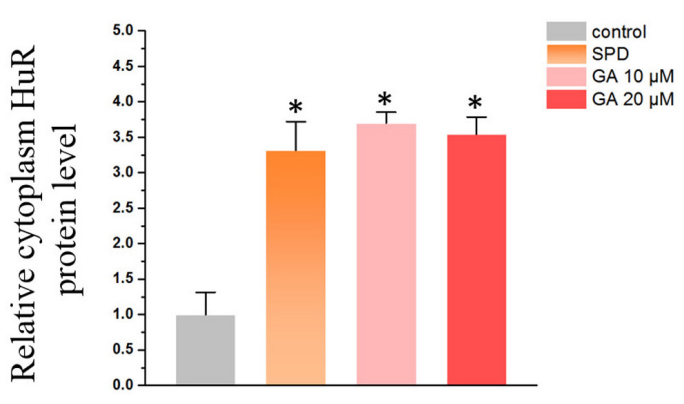

D

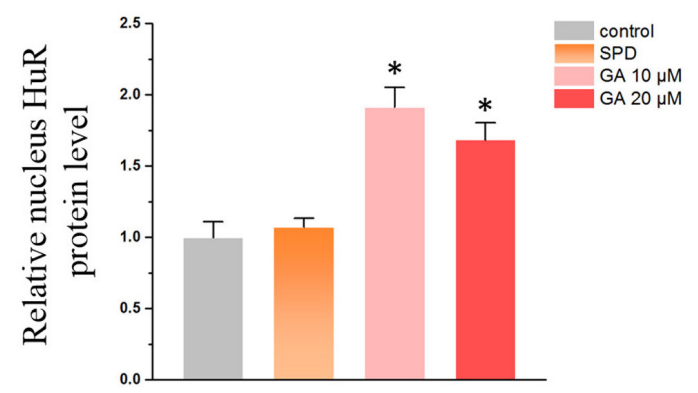

$\mathbf{F}$

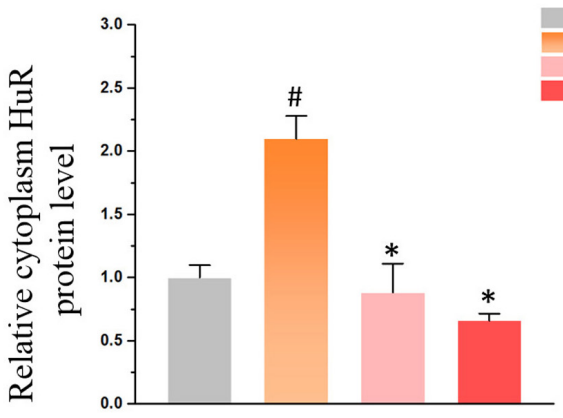

H

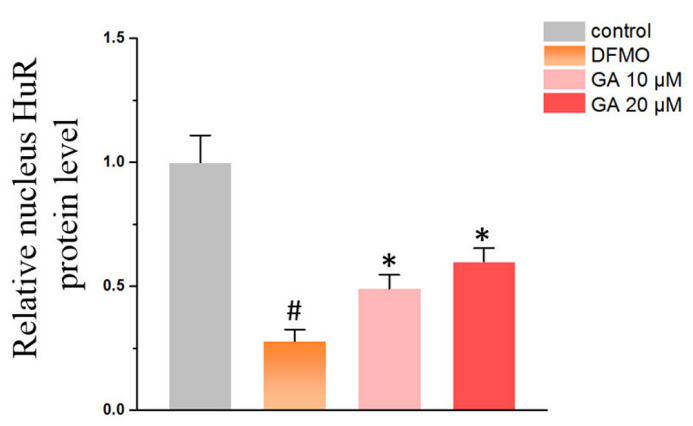

FIGURE 3 | Glycyrrhetinic acid regulates HuR expression in IEC-6 cells. (A) Western blot results showing increased HuR levels in cytoplasm by GA and SPD. (B) Relative HuR levels in IEC-6 cells described in panel (A). Results are referenced to control group. (C) Western blot results showing increased HuR levels in nucleus by GA and SPD. (D) Relative HuR levels in IEC-6 cells described in panel (C). (E) Western blot results show that GA reversed DFMO-induced HuR overexpression in cytoplasm. (F) Relative HuR levels in IEC-6 cells described in panel (E). (G) Western blot results show that GA decreases DFMO-induced HuR down-regulation in nucleus. (H) Relative HuR levels in IEC-6 cells described in panel (G). For panel (B,D), Values are means \pm SEM; $n=6 .{ }^{*} P<0.05$ compared with the control group. For panel (B,D), Values are means \pm SEM; $n=6$. ${ }^{P} P<0.05$ compared with the control group and $* P<0.05$ compared with the DFMO group.

function by increasing epithelial proliferation. Therefore, Caco-2 cells were used to simulate the intestinal barrier (Haines et al., 2016). Generally, during the Caco-2 cell monolayer formation, the rapid proliferation at the early stage (day 1-3) and the formation of barrier functions, such as tight junction, at later stages (day 3-21) are important. We thus used LPS to interfere 
A

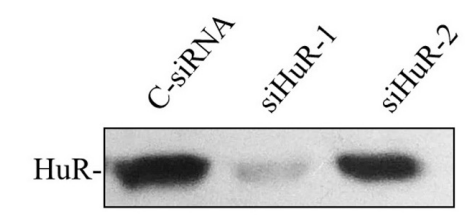

$\beta$-actin-
B

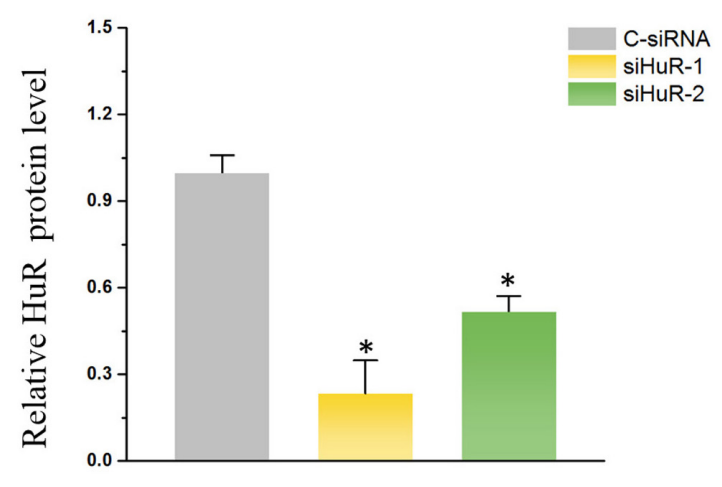

C

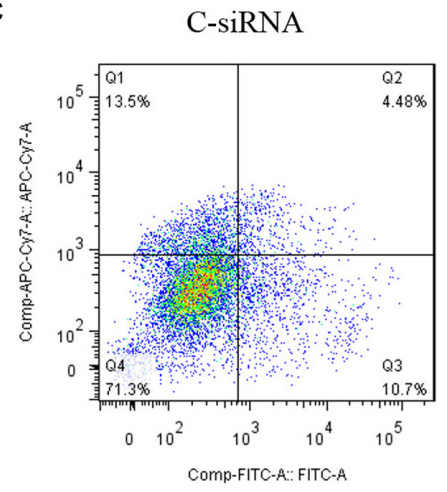

C-siRNA + GA $(10 \mu \mathrm{M})$

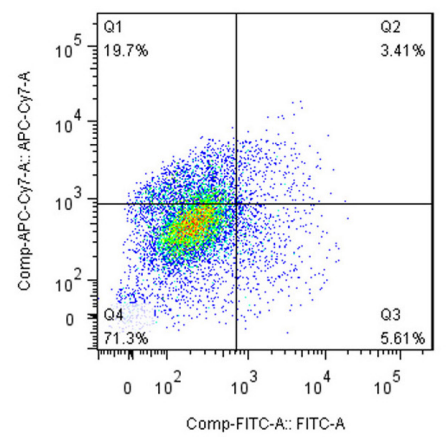

$\mathrm{siHuR}+\mathrm{GA}(10 \mu \mathrm{M})$

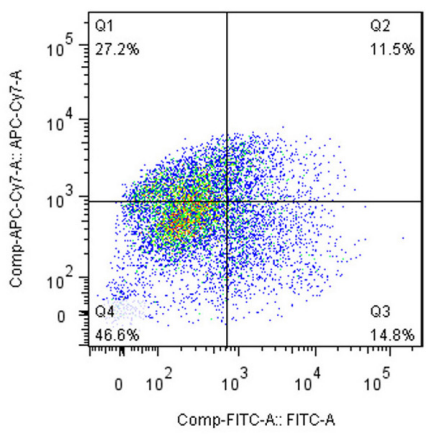

D

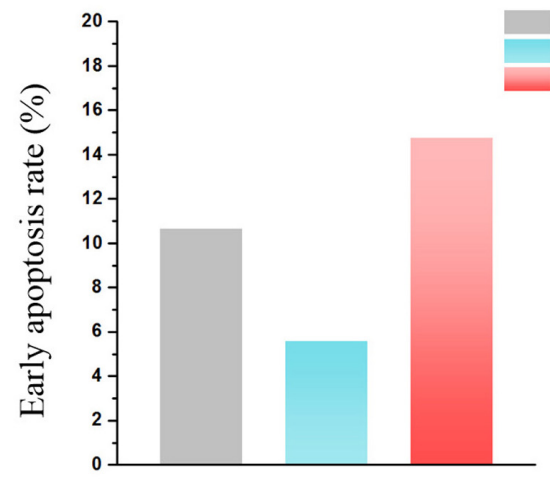

E

C-siRNA

C-siRNA + GA $(10 \mu \mathrm{M})$

siHuR + GA $(10 \mu M)$

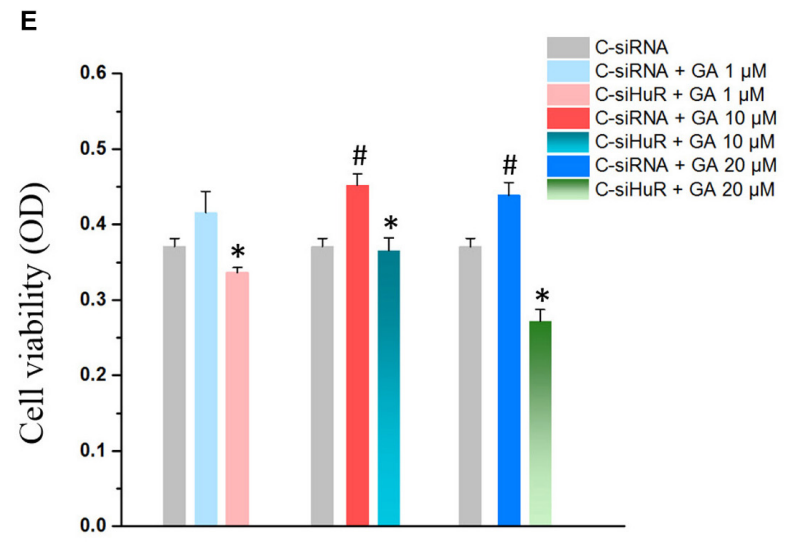

FIGURE 4 | Silencing HuR reverses GA's effect on IEC-6 cells. (A) The siRNA for HuR down-regulates HuR protein levels. Two siRNAs (siRNA1 and siRNA2) were used to down-regulate the HuR protein level, and siRNA1 was adopted in the subsequent experiment for its high efficiency in HuR silence. (B) Summarized data of HuR protein levels described in panel (A). Values are means $\pm \mathrm{SEM} ; n=6 .{ }^{*} P<0.05$ compared with the control siRNA (C-siRNA) group. (C) Flow cytometry results showing apoptosis rates of C-siRNA, GA, and GA+siRNA groups. (D) Summarized data of apoptosis rates described in panel (C). (E) Cell viability results showing the reversing effect of HuR silence on GA-promoted proliferation in IEC-6 cells. Values are means $\pm \mathrm{SEM} ; n=5$. ${ }^{\#}<<0.05$ compared with the control siRNA (C-siRNA) group and $* P<0.05$ compared with C-siRNA + GA groups of various concentration.

with the Caco-2 cell monolayer formation at the early stage and examined if GA rescued the decline in the TEER value caused by LPS through promoting proliferation. In Caco-2 cells,
GA increased HuR levels in cytoplasm (Figures 5A,B). For the Caco-2 cell monolayer model, the TEER value became stable at $59 \mathrm{~h}$ before reaching the ultimate $600 \Omega \cdot \mathrm{cm}^{-2}$ at later stages. 

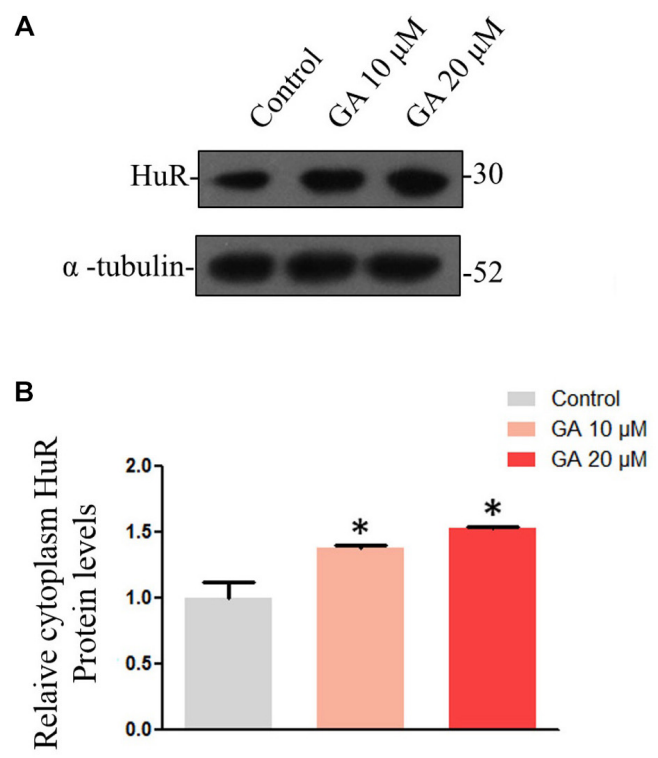

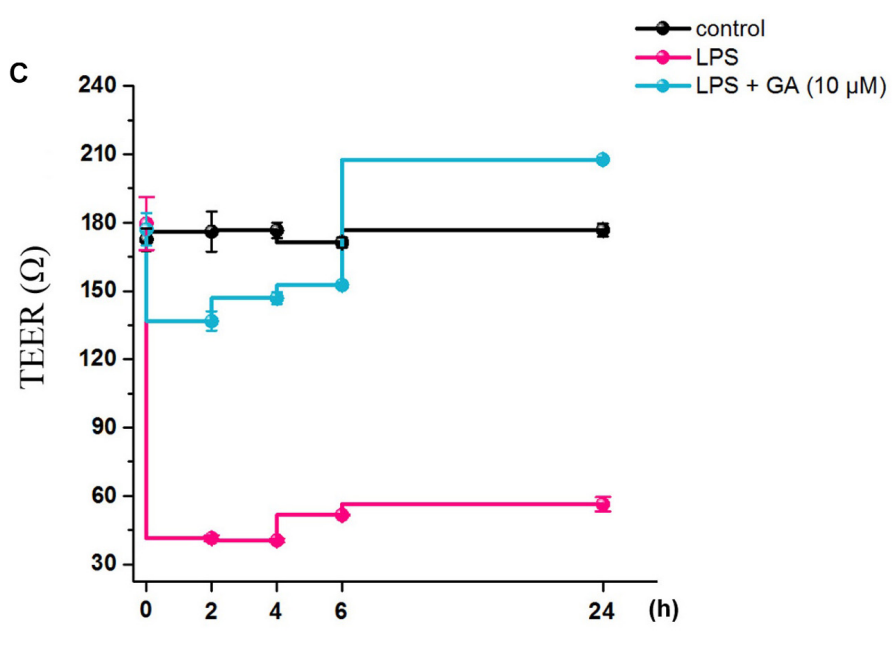

FIGURE 5 | Glycyrrhetinic acid restores the trans-epithelial electrical resistance while increasing cytoplasm HuR protein levels in Caco-2 cells. (A) Western blot results showing increased cytoplasm HuR levels caused by GA in Caco-2 cells. (B) Relative HuR levels in Caco-2 cells described in panel (A). (C) TEER values of each group. Values are means $\pm \mathrm{SEM} ; n=6$. After a 59-h culture, the TEER value of Caco-2 cells becomes stable, and subsequently GA (10 $\mu$ M) was pretreated $2 \mathrm{~h}$ before LPS treatment. ${ }^{*} P<0.05$.

LPS was added at $59 \mathrm{~h}$, and the TEER value of LPS group declined dramatically from $2 \mathrm{~h}$ to $24 \mathrm{~h}$ after LPS treatment. For the GA group, GA $(10 \mu \mathrm{M})$ was added $2 \mathrm{~h}$ before LPS treatment, and TEER values were measured at 2, 4, 6, and $24 \mathrm{~h}$ after LPS treatment. The results showed that GA $(10 \mu \mathrm{M})$ rescued the decline in TEER value induced by LPS to a relatively normal level in a very short time at the early stage of monolayer formation compared with the LPS group (Figure 5C).

\section{GA Promotes the Development of 3D Small Intestinal Organoids via HuR}

The intestinal epithelium develops through the precise process of "intestinal stem cell differentiation, proliferation and migration, and apoptosis." Thus, epithelial stem cells derived from C57BL/6 mouse intestinal small bowel were isolated and used to establish ex vivo culture of intestinal crypt organoids as a $3 \mathrm{D}$ model system for assessing the intestinal epithelium developmentpromoting effect of GA (Matthias et al., 2012; Figure 6A). GA (10 and $20 \mu \mathrm{M}$ ) significantly accelerated the intestinal organoid development as $24 \mathrm{~h}$ after GA treatment, only enterospheres could be found in the control group, while in the GA (10 and $20 \mu \mathrm{M}$ )-treated groups enteroids were already developed (Figure 6B). Furthermore, the ratio of enteroid/enterosphere was used to evaluate the growth rate of intestinal organoids $48 \mathrm{~h}$ after GA treatment (Figures 6C,D). The results showed that GA (10 and $20 \mu \mathrm{M}$ ) potently increased the enteroid/enterosphere ratio, suggesting that GA could drastically stimulate the growth of intestinal organoids. The immunofluorescence results of these ex vivo intestinal organoids $48 \mathrm{~h}$ after GA treatment showed that the proliferative marker ki-67 was significantly raised by GA (10 and $20 \mu \mathrm{M}$ ) treatment (Figure 6E). Moreover, HuR levels in the ex vivo intestinal organoids were also examined, and the results showed that GA $(10$ and $20 \mu \mathrm{M})$ increased the HuR expression while promoting the development of ex vivo intestinal organoids (Figure 6F).

\section{GA Maintains the Small Intestinal Mucosa Integrity via HuR in the Fasting-Induced Intestinal Atrophy}

The model of growth inhibition of the small intestinal mucosa by fasting (Uchida et al., 2017) in rats was adopted so as to evaluate the protective effect of GA on the integrity of small intestinal mucosa. In the model group, the integrity of the small intestinal mucosa was severely undermined (being sparse and thin) and was shortened after $48 \mathrm{~h}$ of fasting, while both 5 and $20 \mathrm{mg} / \mathrm{kg} \mathrm{GA}$ administrated $24 \mathrm{~h}$ prior to the fasting prevented small intestinal mucosa atrophy (Figure 7A). Western blot results showed that HuR was suppressed by the $48 \mathrm{~h}$-fasting, and GA could restore the down-regulated HuR levels in the model group of fasting (48 h) (Figure 7B). Immunofluorescence results substantiated that levels of EGF, EGFR, and MEK, whose mRNAs have AREs in 3'UTR region and were thereby being regulated post-transcriptionally by RBP HuR (Sun et al., 2016), were all down-regulated by $48 \mathrm{~h}$-fasting, and were also restored by GA administration (Figure 7C).

\section{DISCUSSION}

Licorice has been used as an important TCM. There is a saying that nine of ten TCM prescriptions have licorice included, implying its extensive use in TCM. The reason for its broad 
A

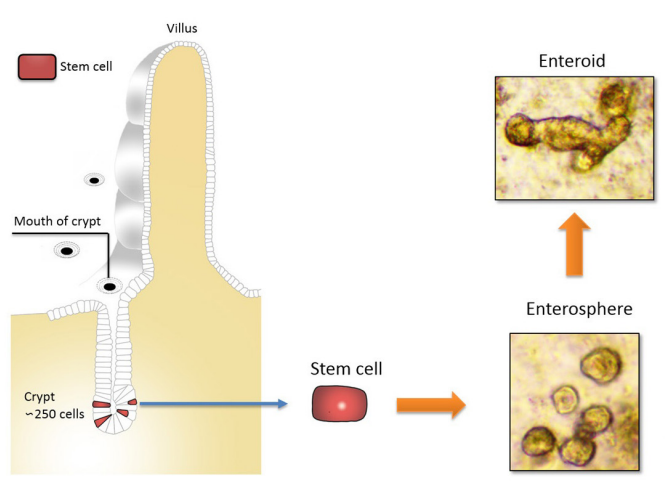

C

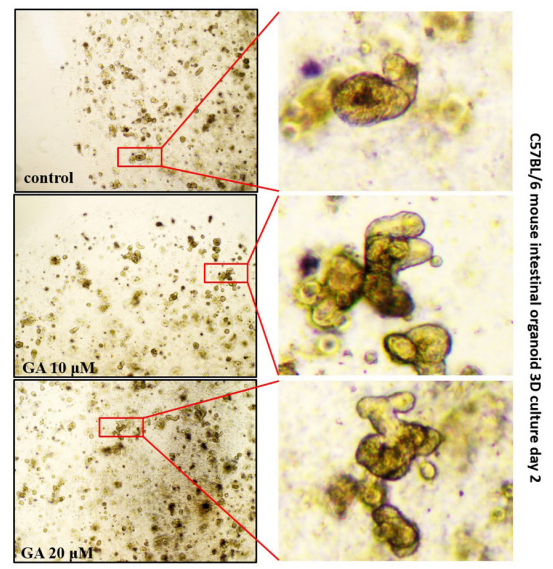

E

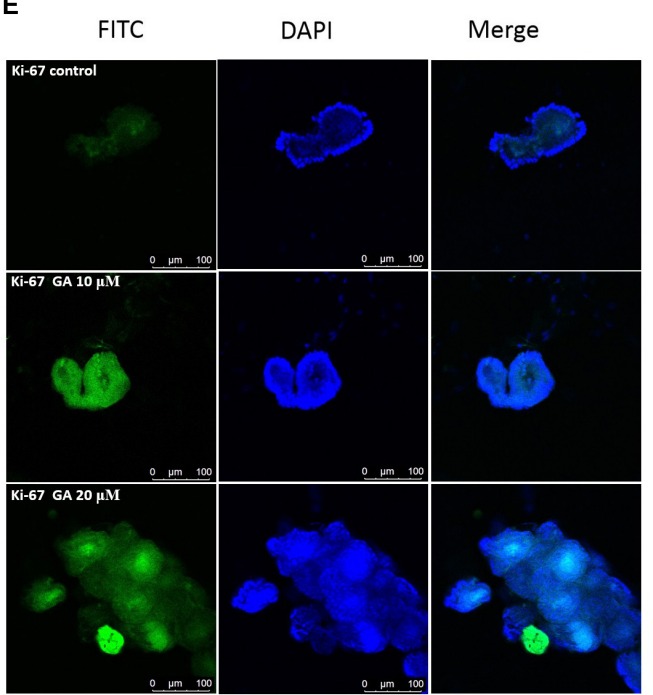

B

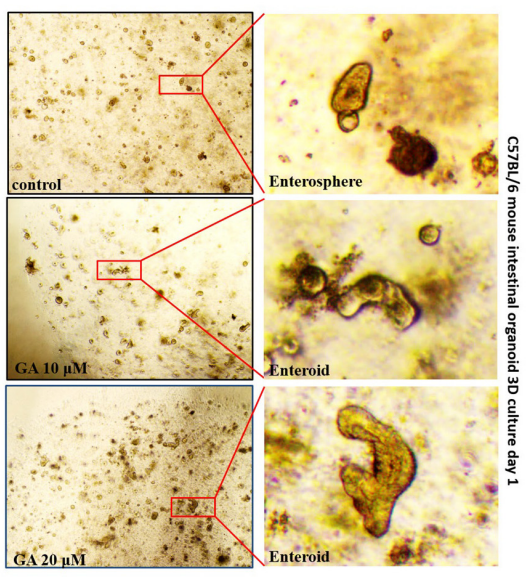

D

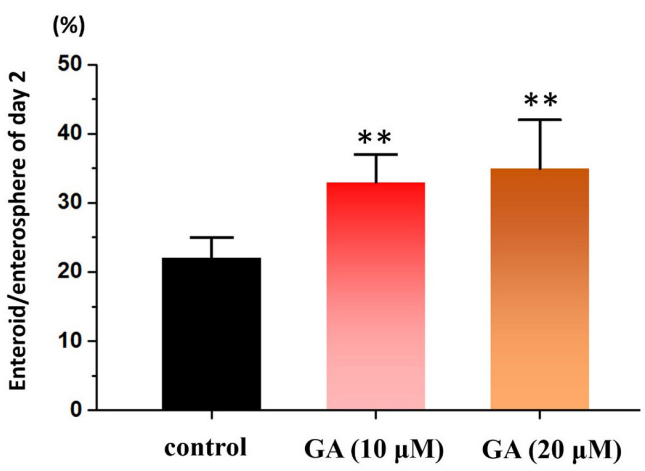

$\mathbf{F}$

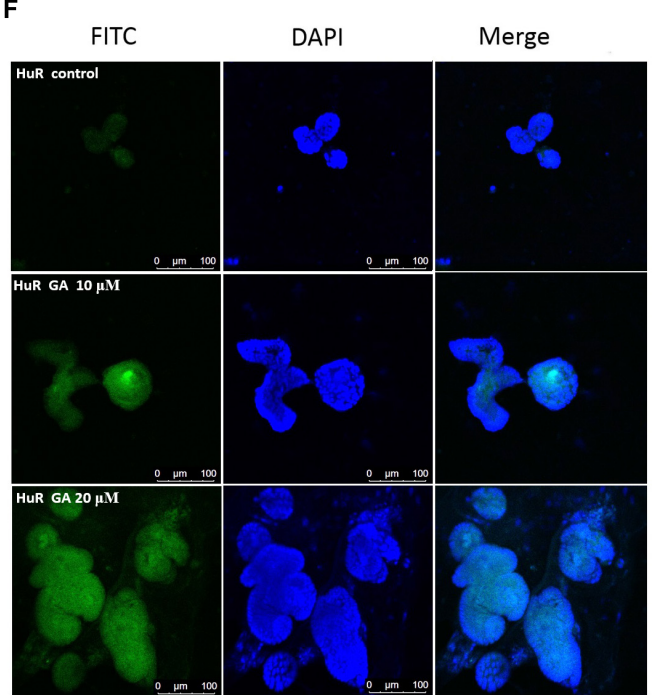

FIGURE 6 | Glycyrrhetinic acid promotes the development of organoids derived from small intestinal crypt. (A) The schematic description of small intestinal crypt stem cell isolation and development in to ex vivo organoids. (B) Development results of day 1 for ex vivo culture of C57BL/6 small intestinal crypt stem cells after GA treatment. The isolated stem cells were cultured $24 \mathrm{~h}$ before GA treatment. (C) Development results of day 2 for ex vivo culture of C57BL/6 small intestinal crypt stem cells after GA treatment. (D) Ratio of enteroid/enterosphere of organoids derived from small intestinal crypt described in panel (C). Higher ratio of enteroid/enterosphere represents faster development of organoids. (E) Immunofluorescence results of ki67 in organoids described in panel (C) for each group. (F) Immunofluorescence results of HuR in organoids described in panel (C) for each group. ${ }^{* *} P<0.01$. 


\section{A}
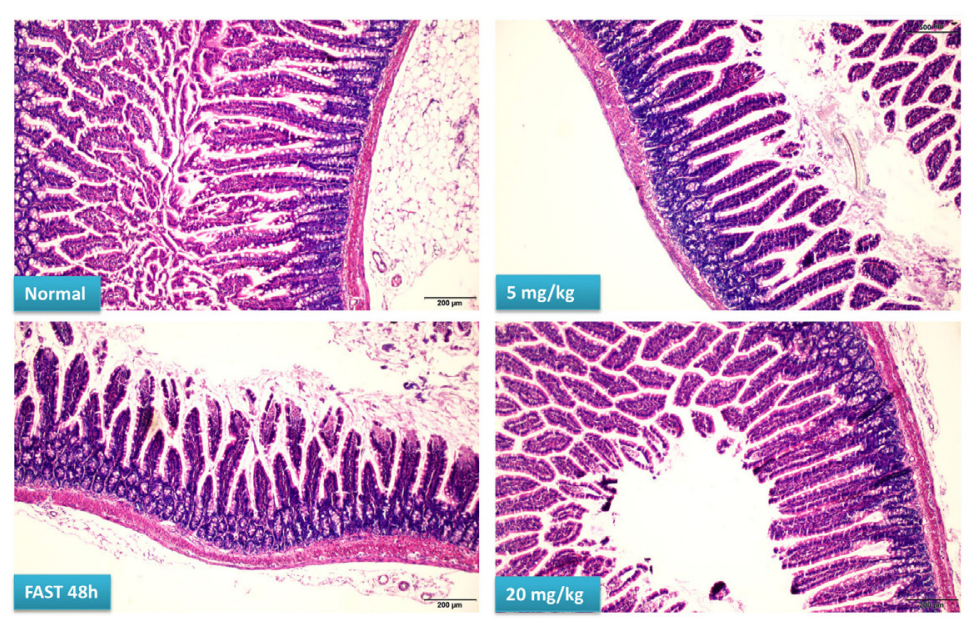

B
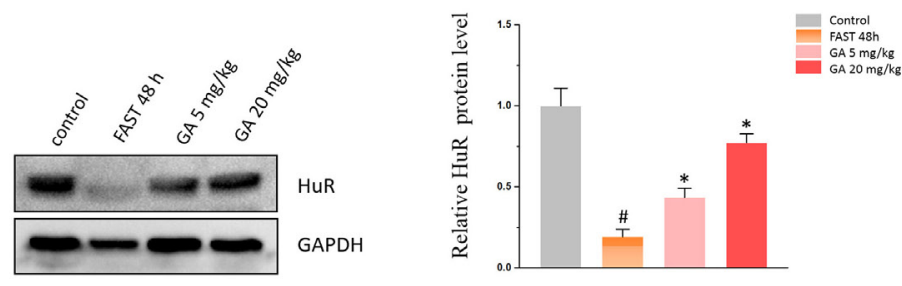

C

EGF
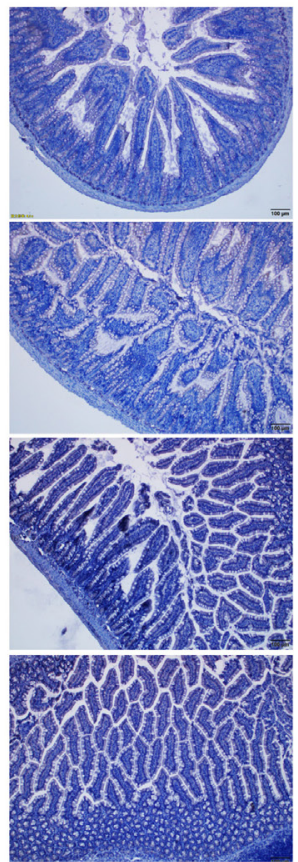

EGFR
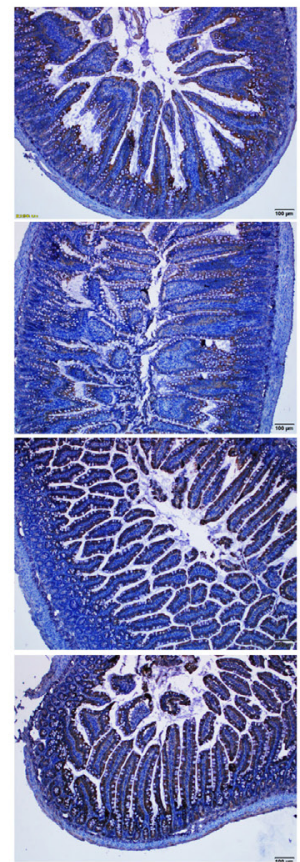

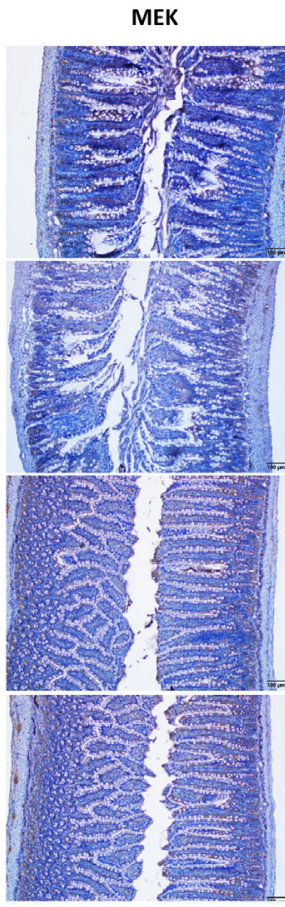

Normal

Fast 48h

$\mathrm{GA} 5 \mathrm{mg} / \mathrm{kg}$

GA $20 \mathrm{mg} / \mathrm{kg}$

FIGURE 7 | Glycyrrhetinic acid prevents fasting-induced intestinal atrophy through HuR. (A) Hematoxylin/eosin staining of the intestinal mucosa. SD rats were deprived of food but allowed free access to tap water for $48 \mathrm{~h}$ in the fasting model. Some rats were given GA (5 mg/kg or $20 \mathrm{mg} / \mathrm{kg} / \mathrm{day}$ once a day) by gavage $24 \mathrm{~h}$ before fasting for 3 days (until the end of fasting). Equal amount of normal saline was given in the control group. (B) Representative immunoblots of HuR in the small intestinal tissue in rats described in panel (A) (left); Relative HuR levels of in the small intestinal tissue in rats described in panel (A) (right). ${ }^{\#} P<0.05$ compared with control group and $* P<0.05$ compared with FAST group. (C) Immunohistochemical results showing EGF, EGFR, and MEK levels in the small intestinal mucosa in rats described in panel (A). 


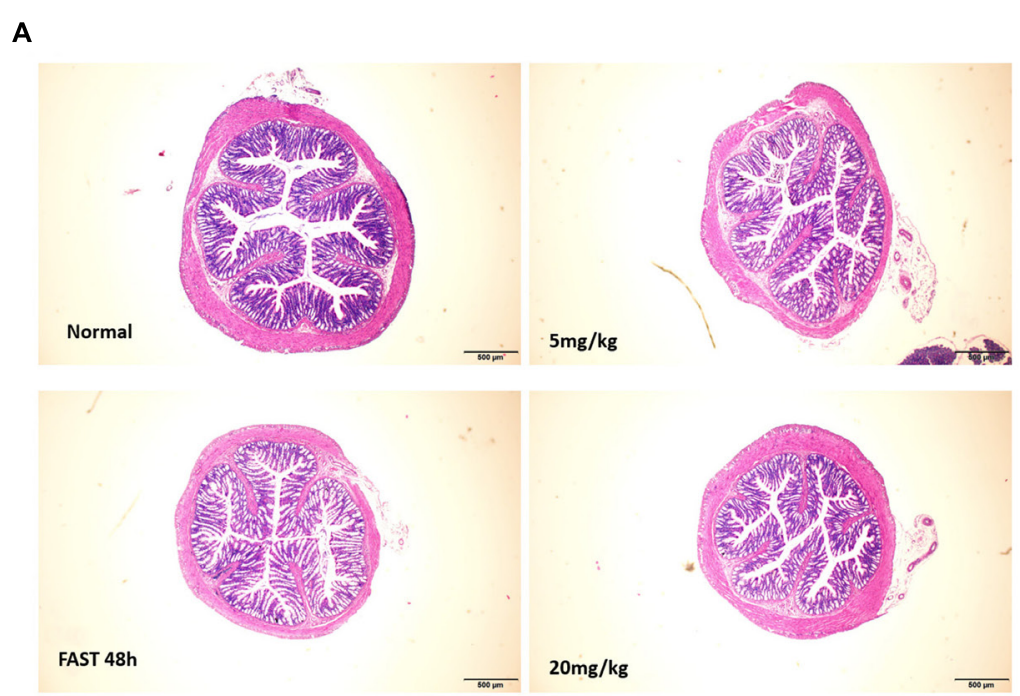

B
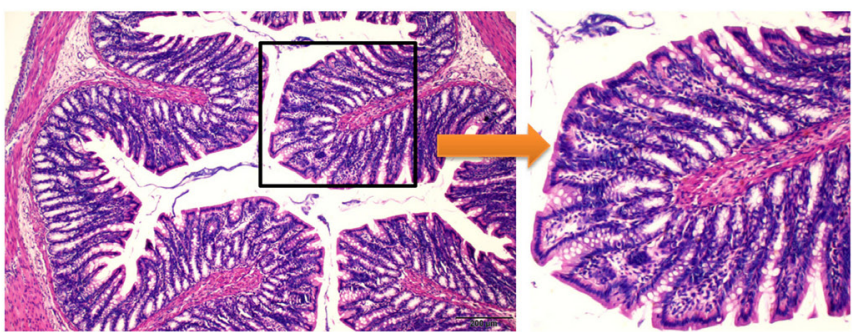

Normal
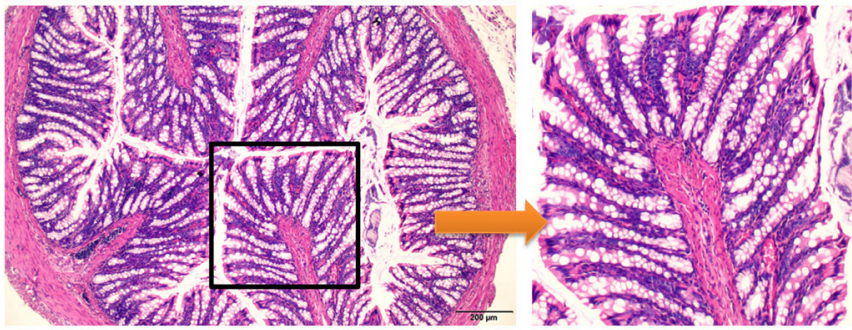

FAST 48h
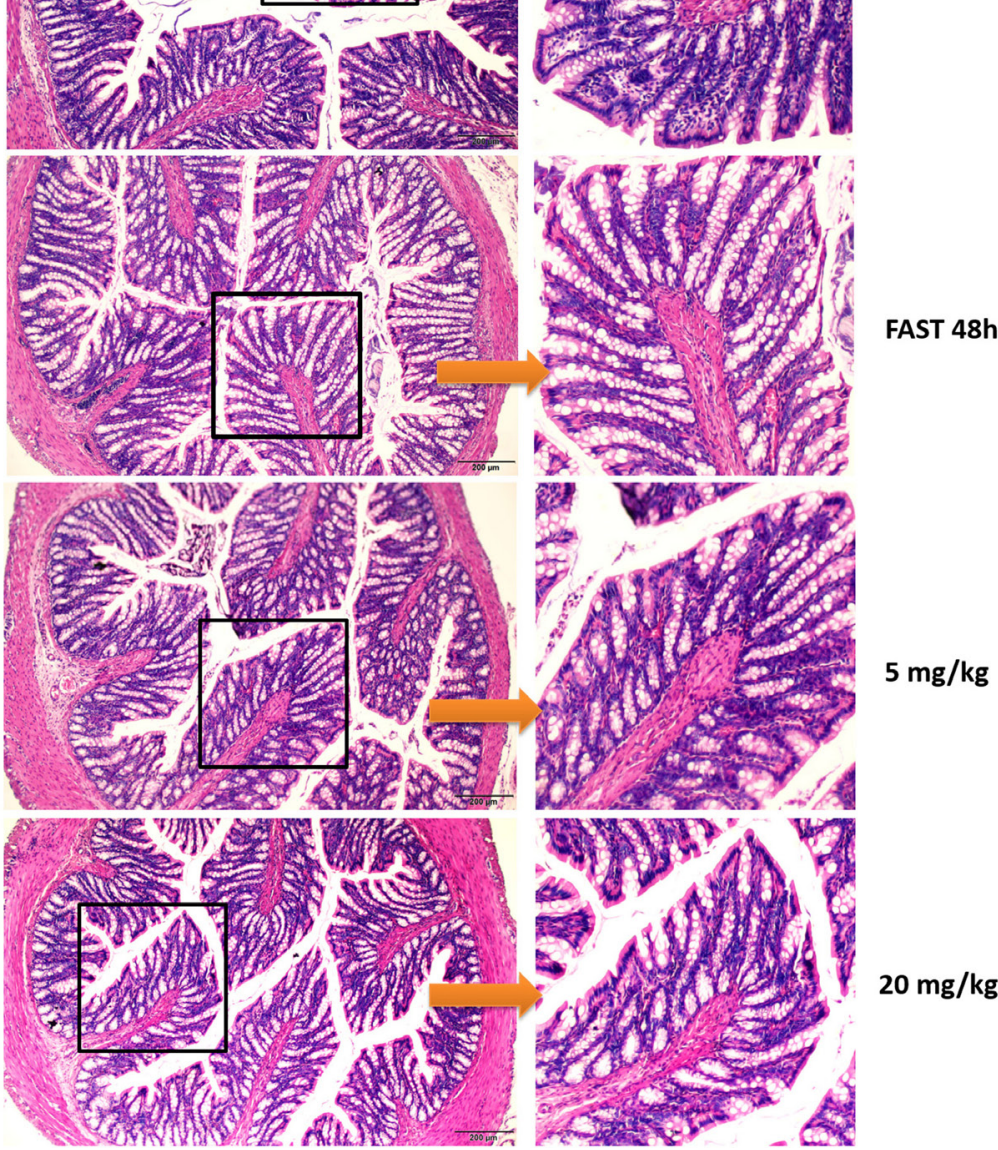

\section{$5 \mathrm{mg} / \mathrm{kg}$}

$20 \mathrm{mg} / \mathrm{kg}$

FIGURE 8 | Glycyrrhetinic acid prevents fasting-induced pathological state in colon tissue through HuR. (A) Hematoxylin/eosin staining of the colon tissue in SD rats described in Figure 7A. (B) Enlarged images of panel (A). 
adoption in TCM can be partially attributed to the TCM theory, according to which licorice is able to coordinate and promote the effects of other medicines co-existing in the same TCM prescription. The classical explanation on this special effect of licorice is that licorice and its main constituent glycyrrhizin can exhibit mineral-corticoid activity and inhibit atrophy of the adrenal cortex (Sasano et al., 1966a,b), and therefore can usually be used as a remedy in case of emergency. However, licorice is consumed as a food and has been utilized more than just in acute diseases. Thus, another potential mechanism for the "coordination effect" of licorice is maintaining the intestinal homeostasis, especially the small intestinal homeostasis, and thereby promoting the absorption of constituents from TCM in the small intestine.

Previous studies revealed that natural molecules can induce the proliferation of IECs (Nishida et al., 2015), and bioactive components from traditional Chinese medicines can also stimulate intestinal epithelial repair (Song et al., 2017). Among them, licorice and its main components exhibited various functions in the intestine. For example, licorice aqueous
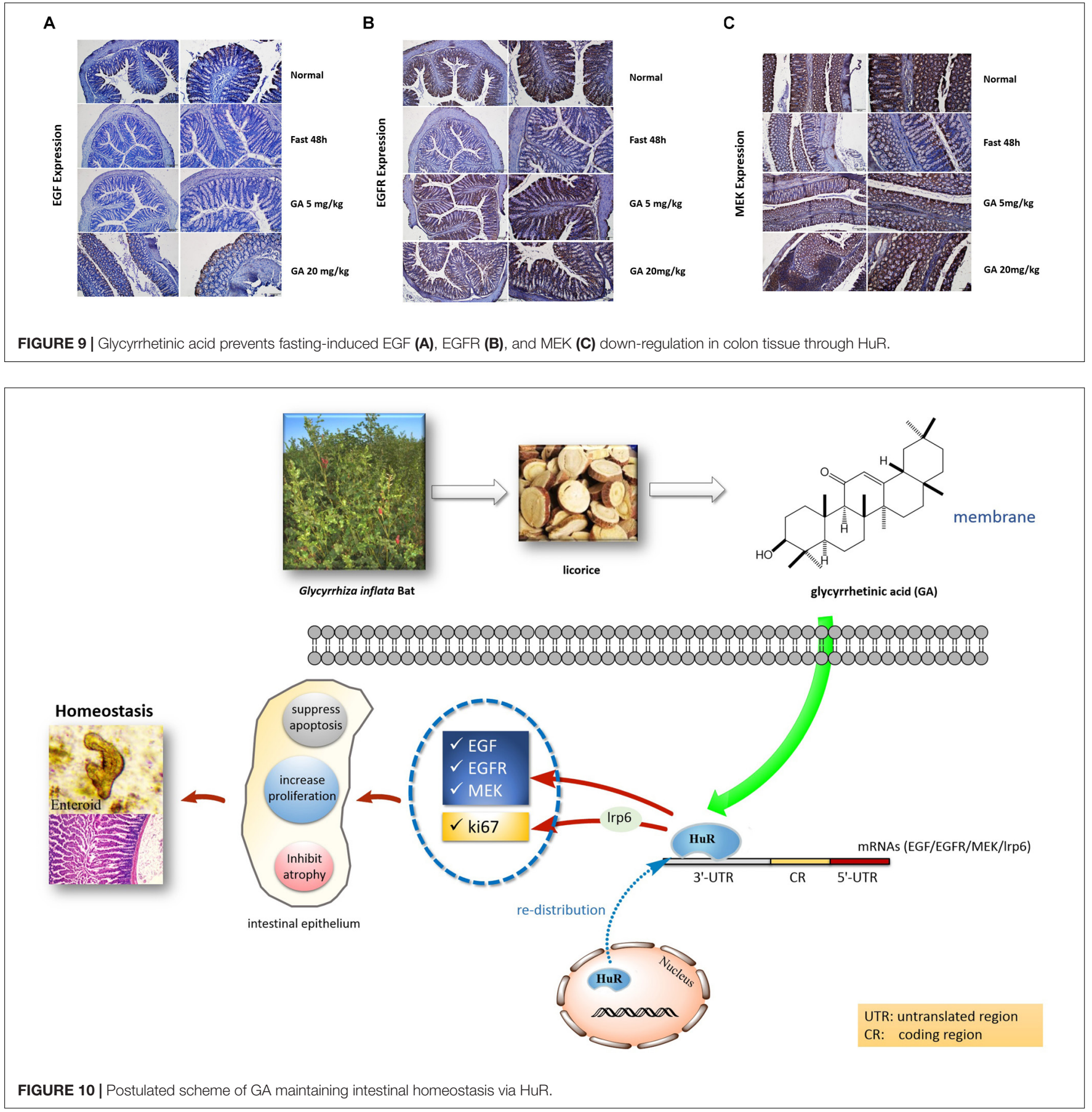
extract can regulate polyamine-depleted intestinal crypt cells proliferation (He et al., 2012); GA from licorice can ameliorate intestinal injury elicited by indomethacin or DSS in mice (Ishida et al., 2013; Jeon et al., 2016). However, the effects on IEC proliferation of molecules from licorice, especially $\mathrm{GA}$, remain unknown.

In this paper, we showed that GA could promote the IEC proliferation, facilitate small intestinal organoid development, and prevent fasting-elicited small intestinal mucosal atrophy, indicating a strong protective activity of GA on the small intestine. Furthermore, a similar protective activity of GA was also found in colon tissues. During the $48 \mathrm{~h}$ of fasting, the number of caliciform cells and mucus significantly increased in the colon tissue, indicating the initiation of "self-defense" against stress states (Figures 8A,B), while GA administration reduced the aberrant morphological features elicited by fasting to a relative normal state (Figures $\mathbf{8 A}, \mathbf{B}$ ) via up-regulating MEK, EGF, and EGFR (Figure 9), suggesting that besides the protective function in the small intestine, GA could also keep the homeostasis of colon tissue and thereby contribute to the reabsorption of drug molecules to maximize the therapeutic effect of the whole prescription.

Recent studies revealed the important role of $\mathrm{HuR}$ in maintaining intestinal homeostasis via the post-transcriptional mechanism (Liu et al., 2016). HuR is a major ARE-binding protein that stabilizes many ARE-mRNAs (Chen et al., 2017). It was suggested that $\mathrm{HuR}$ interacts with $3^{\prime}$-UTR of MEK, EGF, and EGFR mRNAs (Sheflin et al., 2004; Sharma et al., 2013). Our previous research showed that HuR can also interact with the mRNA of Wnt co-receptor lrp6 (Li et al., 2016), and thereby could affect proliferative markers such as ki67 in the Wnt signaling pathway. In this paper, we provided evidence that the GA can increase HuR levels and maintain the homeostasis of the intestinal epithelium. Through increasing the HuR expression, GA increases MEK mRNA stability and promotes its translation to elicit the anti-apoptotic response in IECs (Wang et al., 2010; Figure 4C). Moreover, GA was able to increase EGF levels via $\mathrm{HuR}$ to attenuate the mucosal atrophy elicited by total parenteral nutrition (TPN) or fasting (Feng et al., 2017), thereby maintaining the intestinal homeostasis. Furthermore, GA-induced HuR overexpression enhanced EGFR and ki67

\section{REFERENCES}

Chen, J., Adamiak, W., Huang, G., Atasoy, U., Rostami, A., and Yu, S. (2017). Interaction of RNA-binding protein $\mathrm{HuR}$ and miR-466i regulates GM-CSF expression. Sci. Rep. 7:17233. doi: 10.1038/s41598-017-17371-5

Feng, Y., Demehri, F. R., Xiao, W., Tsai, Y. H., Jones, J. C., Brindley, C. D., et al. (2017). Interdependency of EGF and GLP-2 signaling in attenuating mucosal atrophy in a mouse model of parenteral nutrition. Cell Mol. Gastroenterol. Hepatol. 3, 447-468. doi: 10.1016/j.jcmgh.2016.12.005

Haines, R. J. Jr., Beard, R. S., Chen, L., Eitnier, R. A., and Wu, M. H. (2016). Interleukin-1 $\beta$ mediates $\beta$-Catenin-Driven downregulation of Claudin-3 and barrier dysfunction in Caco2 cells. Dig. Dis. Sci. 61, 2252-2261. doi: 10.1007/ s10620-016-4145-y

He, Y., Zhang, X., Zeng, X., Huang, Y., Wei, J. A., Han, L., et al. (2012). HuRmediated posttranscriptional regulation of $\mathrm{p} 21$ is involved in the effect of expression and in turn promoted the proliferation of intestinal epithelial cells (Lee et al., 2015; Sardi et al., 2017) and facilitated the development of small intestinal crypt stem cells (Figures 6B,C). All these data suggest that GA as a main constituent from licorice could maintain intestinal homeostasis under pathological circumstances via modulating $\mathrm{HuR}$, facilitating the absorption of molecules existing in the traditional Chinese decoction (Figure 10). Thus, our results have provided a new perspective for understanding the coordination effect of licorice.

\section{ETHICS STATEMENT}

The study protocol was approved by the Ethics Committee for Animal Experiments of Guangzhou University of Chinese Medicine (2016-0502).

\section{AUTHOR CONTRIBUTIONS}

GC and NL designed the experiments. XL, YF, JZ, and J-YS analyzed the data. GC wrote the manuscript. BB, D-GQ, and ZJ performed the most of the experiments. All authors critically reviewed and approved the final form of the manuscript.

\section{FUNDING}

The work was supported partially by National Natural Science Foundation of China (Grant Nos. 81660654, 81673323, 81872768, and 81460563), Scientific Research Foundation for Returned Scholars of Shenyang Pharmaceutical University (GGJJ2016103), Science and technology assistance project of Xinjiang (2018E02071), The young and middle-aged teachers' career development support plan of Shenyang Pharmaceutical University (2017), Tianshan youth program of Xinjiang (2017Q066), Foundation of Jilin Provincial Education Department (2016-284), Natural Science Foundation of Jilin Province, Jilin, China (Grant Nos. 20160101154JC and 20190701034GH), and LiaoNing Revitalization Talents Program (XLYC1807118).

Glycyrrhiza uralensis licorice aqueous extract on polyamine-depleted intestinal crypt cells proliferation. J. Nutr. Biochem. 23, 1285-1293. doi: 10.1016/j.jnutbio. 2011.07.009

Ishida, T., Miki, I., Tanahashi, T., Yagi, S., Kondo, Y., Inoue, J., et al. (2013). Effect of $18 \beta$-glycyrrhetinic acid and hydroxypropyl $\gamma$ cyclodextrin complex on indomethacin-induced small intestinal injury in mice. Eur. J. Pharmacol. 714, 125-131. doi: 10.1016/j.ejphar.2013.06.007

Jeon, Y. D., Kang, S. H., Bang, K. S., Chang, Y. N., Lee, J. H., and Jin, J. S. (2016). Glycyrrhetic acid ameliorates dextran sulfate sodiuminduced ulcerative colitis in vivo. Molecules 21:523. doi: 10.3390/molecules210 40523

Lee, M., Kim, I., Choi, Y., Choi, J., Kim, Y., and Nam, T. (2015). The proliferative effects of Pyropia yezoensis peptide on IEC-6 cells are mediated through the epidermal growth factor receptor signaling pathway. Int. J. Mol. Med. 35, 909-914. doi: 10.3892/ijmm.2015.2111 
Li, Y., Chen, G., Wang, J. Y., Zou, T., Liu, L., Xiao, L., et al. (2016). Posttranscriptional regulation of Wnt co-receptor LRP6 and RNA-binding protein HuR by miR-29b in intestinal epithelial cells. Biochem. J. 473, 1641-1649. doi: 10.1042/BCJ20160057

Liu, L., Zhuang, R., Xiao, L., Chung, H. K., Luo, J., Turner, D. J., et al. (2016). $\mathrm{HuR}$ enhances early restitution of the intestinal epithelium by increasing $\mathrm{Cdc} 4^{2}$ translation. Mol. Cell. Biol. 37:e574-16. doi: 10.1128/MCB.00574-16

Matthias, S., Michael, H., Dunn, J. C. Y., Henning, S. J., Houchen, C. W., Calvin, K., et al. (2012). A nomenclature for intestinal in vitro cultures. Am. J. Physiol. Gastrointest. Liver Physiol. 302:G1359-63. doi: 10.1152/ajpgi.00493.2011

Mccue, M. D., Passement, C. A., and Meyerholz, D. K. (2017). Maintenance of distal intestinal structure in the face of prolonged fasting: a comparative examination of species from five vertebrate classes. Anat. Rec. 300, 2208-2219. doi: 10.1002/ar.23691

Nishida, M., Murata, K., Oshima, K., Itoh, C., Kitaguchi, K., Kanamaru, Y., et al. (2015). Pectin from Prunus domestica L. induces proliferation of IEC-6 cells through the alteration of cell-surface heparan sulfate on differentiated Caco-2 cells in co-culture. Glycoconj. J. 32, 153-159. doi: 10.1007/s10719-015-9588-4

Sardi, C., Luchini, P., Emanuelli, A., Giannoni, A., Martini, E., Manara, L. M., et al. (2017). Three months of Western diet induces small intestinal mucosa alteration in TLR KO mice. Microsc. Res. Tech. 80, 563-569. doi: 10.1002/jemt. 22831

Sasano, N., Miyazawa, H., Shimizu, K., and Hirano, K. (1966a). Effects of glycyrrhizin on dexamethasone-induced atrophy of the adrenal cortexhistopathological and enzyme histochemical studies. Nihon Naibunpi Gakkai Zasshi 42, 657-664.

Sasano, N., Miyazawa, H., Shimizu, K., and Koizumi, K. (1966b). Stimulation of rat adrenocortical cells by glycyrrhizin with special reference to its inhibitory effect on dexamethasone-induced atrophy of the adrenal cortex. Tohoku J. Exp. Med. 90, 391-403.

Sharma, S., Verma, S., Vasudevan, M., Samanta, S., Thakur, J. K., and Kulshreshtha, R. (2013). The interplay of HuR and miR-3134 in regulation of AU rich transcriptome. RNA Biol. 10, 1283-1290. doi: 10.4161/rna.25482

Sheflin, L. G., Zou, A. P., and Spaulding, S. W. (2004). Androgens regulate the binding of endogenous HuR to the AU-rich $3^{\prime}$ UTRs of HIF- $1 \alpha$ and EGF mRNA.
Biochem. Biophys. Res. Commun. 322, 644-651. doi: 10.1016/j.bbrc.2004. 07.173

Song, H. P., Hou, X. Q., Li, R. Y., Yu, R., Li, X., Zhou, S. N., et al. (2017). Atractylenolide I stimulates intestinal epithelial repair through polyaminemediated Ca2+ signaling pathway. Phytomedicine 28, 27-35. doi: 10.1016/j. phymed.2017.03.001

Song, H. P., Li, R. L., Chen, X., Wang, Y. Y., Cai, J. Z., Liu, J., et al. (2014). Atractylodes macrocephala Koidz promotes intestinal epithelial restitution via the polyamine-voltage-gated $\mathrm{K}+$ channel pathway. J. Ethnopharmacol. 152, 163-172. doi: 10.1016/j.jep.2013.12.049

Sun, S., Zhang, X., Lyu, L., Li, X., Yao, S., and Zhang, J. (2016). Autotaxin expression is regulated at the post-transcriptional level by the RNA-binding proteins HuR and AUF1. J. Biol. Chem. 291, 25823-25836. doi: 10.1074/jbc.M116.75 6908

Uchida, H., Nakajima, Y., Ohtake, K., Ito, J., Morita, M., Kamimura, A., et al. (2017). Protective effects of oral glutathione on fasting-induced intestinal atrophy through oxidative stress. World J. Gastroenterol. 23, 6650-6664. doi: 10.3748/wjg.v23.i36.6650

Wang, P. Y., Rao, J. N., Zou, T., Liu, L., Xiao, L., Yu, T. X., et al. (2010). Posttranscriptional regulation of MEK-1 by polyamines through the RNA-binding protein $\mathrm{HuR}$ modulating intestinal epithelial apoptosis. Biochem. J. 426, 293-306. doi: 10.1042/BJ2009 1459

Conflict of Interest Statement: The authors declare that the research was conducted in the absence of any commercial or financial relationships that could be construed as a potential conflict of interest.

Copyright $\odot 2019$ Chen, Bei, Feng, Li, Jiang, Si, Qing, Zhang and Li. This is an open-access article distributed under the terms of the Creative Commons Attribution License (CC BY). The use, distribution or reproduction in other forums is permitted, provided the original author(s) and the copyright owner(s) are credited and that the original publication in this journal is cited, in accordance with accepted academic practice. No use, distribution or reproduction is permitted which does not comply with these terms. 